\title{
DEVELOPMENT OF MULTISTITCHED THREE-DIMENSIONAL (3D) NANOCOMPOSITE AND EVALUATION OF ITS MECHANICAL AND IMPACT PROPERTIES
}

\author{
Kadir Bilisik*1, Huseyin Ozdemir ${ }^{2}$ and Gaye Kaya ${ }^{3}$
}

\author{
${ }^{1}$ Erciyes University, Engineering Faculty, Department of Textile Engineering, 38039 Talas-Kayseri, Turkey \\ ${ }^{2}$ Gaziantep University, Vocational School of Technical Sciences, Department of Textile Technology, 27310 Sehitkamil-Gaziantep, Turkey \\ ${ }^{3}$ Kahramanmaras Sutcu Imam University, Faculty of Engineering and Architecture, Department of Textile Engineering, 46100 Kahramanmaras, Turkey \\ ${ }^{*}$ Corresponding author: Kadir Bilisik; E-mail: kadirbilisik@gmail.com
}

\begin{abstract}
:
Multistitched three-dimensional (3D) woven E-glass/polyester/nanosilica composite (MNS) was developed. Its mechanical and impact performances were characterized for particular end-use applications. It was found that the warp-weft directional tensile strength and modulus of MNS structure were higher than those of the off-axis directions. In addition, there was not a big difference between warp and weft directional bending and short beam strengths of MNS structure. The MNS structure had a small damaged area under low velocity impact load. The failure was confined at a narrow area because of multistitching and nanomaterial and resulted in the catastrophic fiber breakages in the normal direction of the applied load of the structure. The results from the study indicated that the multistitching and the addition of nanosilica in the composite structure improved its damage tolerance.
\end{abstract}

\section{Keywords:}

Multistitched 3D preform; multistitched composite; warp-weft tensile strength; failure modes; low velocity impact.

\section{Introduction}

Textile composites have been used in various industrial and ballistic areas because of their high stiffness-to-weight ratio and damage tolerance properties [1, 2]. Textile preforms are made by weaving, braiding, knitting, stitching, and nonwoven techniques [3]. A stitching in textile composites improved the tensile and flexural properties of the two-dimensional (2D) woven composite through the distribution of the stress among the layers by the load transfer of stitching yarn [4]. The delamination crack propagation in 2D stitched woven composites was suppressed by using the high linear density stitching yarns [5]. It was reported that adding a few percentage of stitching yarn to the out-of-plane direction of the composite improved the thickness direction mechanical properties [6]. It was shown that the high stitch density was better at impeding delamination growth by arresting cracks at closer interval and suppressing crack propagation [7]. On the other hand, it was found that the in-plane shear strength and modulus of the multiaxis 3D woven carbon composite were higher than those of the 3D orthogonal woven carbon composite. However, the bending strength, bending modulus, and interlaminar shear strength of the multiaxis 3D woven carbon composite were slightly lower than those of the 3D orthogonal woven carbon composite. This was because of the orientations of the \pm bias yarns on both surfaces of the multiaxis $3 D$ woven structure $[8,9]$. The interlaminar shear strengths of the nanoparticlemodified composites were significantly improved $(16 \%)$ by adding only 0.3 wt. \% of carbon nanotubes [10]. The nanomodified composite possessed a higher stiffness and strainto-failure. The nano-modified composite cracks progressed through the material in smaller jumps than in the non-nanotubes composite [11]. It was reported that the properties of nanostructured composites were highly structure/size dependent [12]. The high degree of particle clustering led to lower modulus of the nanocomposites. The shape of nanoparticles has a strong effect on the elastic properties of the nanocomposites. The most effective reinforcement was cylindrical one, followed by ellipsoids, discs, and spheres [13]. The modulus of the composite increased by adding silicon carbide ( $\mathrm{SiC}$ ) nanoparticles regardless of the dispersion quality, whereas strength was highly sensitive to dispersion quality and increased with the addition of the coupling agent and dispersant. Hence, a well-dispersed $\mathrm{SiC}$ was required to improve the quality of the nanocomposite [14]. In addition, the tensile strength of the E-glass/unsaturated isophthalic polyester composite decreased by increasing the SiC particle. The reasons were that the weak bonding at the interface between the SiC particles and the matrix and the particle geometry that resulted in stress concentration in the polyester matrix [15]. The aminefunctionalized single-wall carbon nanotubes (a-SWCNTs) incorporated at the fiber/fabric-matrix interfaces of a 2D woven carbon/epoxy composite showed improvement in the tensile strength-stiffness and the tensile-tensile fatigue damage [16]. It was claimed that the predispersed over-coating nanotubes and the processing modification led to the enhancement of the interface properties of 2D woven E-glass/vinyl ester composites partly because of Z-directional reinforcements [17]. It was also found that nanotubes with amine functional groups have better tensile strength, as compared to those with untreated carbon nanotubes (CNTs) [18]. It was also reported that the $0.5 \mathrm{wt}$. $\%$ amino-functionalized double-wall CNTs/epoxy composites enhanced the fracture toughness of composites [19]. 
The uniform distribution of stitching yarns in the woven composite resulted better in-plane tensile and impact strengths [20]. Contrarily, it was reported that the three-point flexural strength of two-directional stitched E-glass/vinylester composite structures was reduced by stitching and stitched induced stress concentration sites [21, 22]. The stitching in the through-the-thickness direction increased impact damage performance. A strong correlation of energy absorption with respect to stitching yarn fracture works in relation to its fiber volume fraction was found [23]. Stitching improved the damage resistance properties of woven composite structure under blast load and ballistic impact load [24]. It was reported that stitching fiber base composites in the through-the-thickness direction enhanced the Mode I and Mode II interlaminar fracture toughness, which was experimentally determined by using double cantilever beam and an end-notched flexure test, respectively $[25,26]$. The critical strain-energy release rate increased because the stitching bridge the delamination [27, 28].

Another study showed that 3D orthogonal woven E-glass/vinyl ester composite had the greatest resistance to penetration under low-velocity impact and dissipated more total energy than 2D plain woven E-glass/vinyl ester and 2D biaxial warp knitted E-glass/vinyl ester composites. This is due to the unique energy absorption mechanism that involves the crimped portion of Z-fiber in the structure and implies that failure can be controlled by the manipulation of the properties of the Z-fibers. The distinctive modes of failure for all materials were matrix cracking, delamination or debonding, and fiber fracture [29]. On the other hand, the S-glass/epoxy silica nanoclays into structure led not only to better stiffness but also to an increase in impact resistance and fracture toughness, which changed the failure mechanism from interlaminar to intralaminar [30]. Recently, it was demonstrated that when the stitching density and the number of stitching directions increased, the front and back face damaged areas generally decreased under the lowvelocity impact load [31].

The objective of this study was to develop 3D nanocomposite structures by multistitching in used woven E-glass fabric/ polyester resin and nanosilica material and to experimentally characterize the mechanical and low-velocity impact properties.

\section{Experimental}

\subsection{Materials}

\section{Multistitched 3D woven E-glass/polyester nano preform and composite}

E-glass woven fabric (Cam Elyaf INC., Turkey) was used to make multistitched multilayered woven (3D) structures. The

Table 1. Specifications of high modulus fiber, matrix, nano, stitched yarn and fabric for making composite.

\begin{tabular}{|c|c|c|c|c|c|}
\hline & $\begin{array}{c}\text { E-glass fiber } \\
\text { (Cam Elyaf } \\
\text { Inc., TR) }\end{array}$ & $\begin{array}{l}\text { Polyester } \\
\text { Resin } \\
\text { (Crystic } \\
\text { 703PA, Scott } \\
\text { Bader, UK) }\end{array}$ & $\begin{array}{c}\text { Nano silica } \\
\text { (SiO2) } \\
\text { (Sigma- } \\
\text { Aldrich, DE) }\end{array}$ & $\begin{array}{c}\text { E-glass fabric } \\
\text { (Cam Elyaf } \\
\text { Inc., TR) }\end{array}$ & $\begin{array}{c}\text { Stitched yarn } \\
\text { Kevlar } 129 \text { / } \\
\text { Nylon } 6.6 \\
\text { (DuPont, USA) }\end{array}$ \\
\hline Fiber diameter $(\mu)$ & 17 & - & - & - & $12 / 14$ \\
\hline Density $\left(\mathrm{g} / \mathrm{cm}^{3}\right)$ & 2.56 & 1.20 & $2.2-2.6$ & - & $1.45 / 1.14$ \\
\hline Density (warp/weft, per $10 \mathrm{~cm}$ ) & - & - & - & $16 / 18$ & - \\
\hline Yarn linear density (tex) & - & - & - & 2400 & $110 / 44$ \\
\hline Weight $\left(g / m^{2}\right)$ & - & - & - & 800 & - \\
\hline Crimp (warp/weft, \%) & - & - & - & $1.24 / 1.20$ & - \\
\hline Thickness (mm) & - & - & - & 1.01 & - \\
\hline Tensile strength (GPa) & 3.5 & 0.049 & 0.11 & - & $3.4 / 0.6$ \\
\hline Tensile modulus (GPa) & 76 & 2.8 & 73 & - & $99 / 2.46$ \\
\hline Elongation at break (\%) & 4.8 & 2.1 & - & - & $3.3 / 41$ \\
\hline Melting point $\left(\mathrm{C}^{\circ}\right)$ & 841 & - & $>1600$ & - & $\begin{array}{c}\text { 550/265 } \\
\text { Decompose } \\
\text { /melt }\end{array}$ \\
\hline Particle size (Average, nm) & - & - & $30.80 \pm 8.6$ & - & - \\
\hline Molecular weight $(\mathrm{g} / \mathrm{mol})$ & - & - & 60.1 & - & - \\
\hline Purity (\%) & - & - & 99.5 & - & - \\
\hline Surface area $\left(\mathrm{m}^{2} / \mathrm{g}\right)$ & - & - & $140-180$ & - & - \\
\hline Weave type & - & - & - & Plain & - \\
\hline
\end{tabular}


fiber, matrix, nano, stitching yarn, and fabric specifications are presented in Table 1. E-glass fabric was made from 2,400 tex fibers. The E-glass fabric was plain weave. The warp and filling densities of the E-glass fabric were 16 and 18 ends/10 $\mathrm{cm}$, respectively. The warp and filling crimp ratios of E-glass fabric were $1.24 \%$ and $1.20 \%$, respectively. The fabric unit areal weight was $800 \mathrm{~g} / \mathrm{m}^{2}$, and fabric thickness was 1.01 $\mathrm{mm}$. The type of nanomaterials were selected based on the compatibility with E-glass fabric, better impact properties, commercial availability, and cost effectiveness. The size of nanoparticle varied from 30 to $40 \mathrm{~nm}$ and was chosen sphere shapes. Crimp measurement was performed using a Tautex digital instrument (James H. Heal Co., UK). The fabric weight measurement was performed using an Ohaus AdventurerTM Pro AV812 (Ohaus Corp., USA) digital balance. The fabric thickness measurement was performed using an EV07 digital device (Elastocon, Sweden).

Multistitched 3D E-glass/polyester nanosilica composite structures (MNS) was developed. The multistitched structure was a layered fabric $\left[\left(0^{\circ} / 90^{\circ}\right)\right]_{4}$, in which four biaxial fabric stacked layer by layer all together, was defined as the structure was stitched on $0^{\circ}$ (warp), $90^{\circ}$ (filling), and $\pm 45^{\circ}$ (diagonal of the warp) directions. The multistitched structures was made by machine stitching. Figure 1 shows the schematic views of machine multistitching on $0-90^{\circ}$ and $\pm 45^{\circ}$ directions. Lock stitching was used, and the stitching density was 6 step/cm. The distance between the adjacent stitching lines was $1 \mathrm{~cm}$. The stitching yarns were Kevlar ${ }^{\circledR} 129$ as the bobbin stitching yarn and nylon 6.6. as the needle stitching yarn. The stitching machine was produced by Brother Industries Ltd. DB2-B7363TR, Japan. The stitching yarn, namely, Kevlar 129, made double ends, and its loop was secured by nylon 6.6 yarn during insertion to the preform structure. The properties of the stitching yarn is presented in Table 1. Figure 2 shows the multistitched 3D E-glass/polyester nanosilica preforms and composites.

Multistitched 3D E-glass/polyester preforms were consolidated to make composites. Figure 3 shows the infusion of the resin to the preform to make the composite with vacuum-assisted resin transfer molding (VaRTM). Dicyclopentadiene-based unsaturated polyester resin (Crystic 703PA, Scott Bader, UK) was used. Methyl ethyl ketone peroxide (MEKP) was used as hardener, $2 \%$ by weight of resin to produce neat E-glass/ polyester composites. The polyester resin and hardener were mixed homogeneously and applied to the preforms under vacuum at $20^{\circ} \mathrm{C}$. In addition, catalyst (Cobalt naphthenate (CoNAP)) was also used to produce nanocomposite structures. Amounts of MEKP and CoNAP by weight of resin and mixing conditions are presented in Table 2. Nanomaterials were mixed first with polyester resin including MEKP and CoNAP by a mechanical stirrer (IKA-T25 Digital Ultra Turrax, IKA® Werke $\mathrm{GmbH}$ \& Co. KG) in which mixing was gradually carried out starting from 3,000 to $20,000 \mathrm{rpm}$, stay for $2 \mathrm{~min}$, and then from 20,000 to $3,000 \mathrm{rpm}$. Later on, mixing was continued in ultrasonic bath, $5 \mathrm{~min}$ at $25^{\circ} \mathrm{C}$, to get homogeneous distribution of silica nanoparticles in the polyester resin. After that, matrix was vacuumed to get rid of the air bubble, and finally, hardener and catalyst were added. This matrix was applied to the preform under vacuum at $20^{\circ} \mathrm{C}$. The density of the multistitched $3 \mathrm{D}$ woven E-glass/polyester nanocomposite was determined by ASTM D792-91 [32]. The composite volume fraction and void content were determined by ASTM D3171-99 [33] and ASTM D2734-91 [34], respectively. Before the low-velocity impact test, the stitching area of the composite sample was examined by a scanning electron microscope (SEM; LEO 440® model, UK).

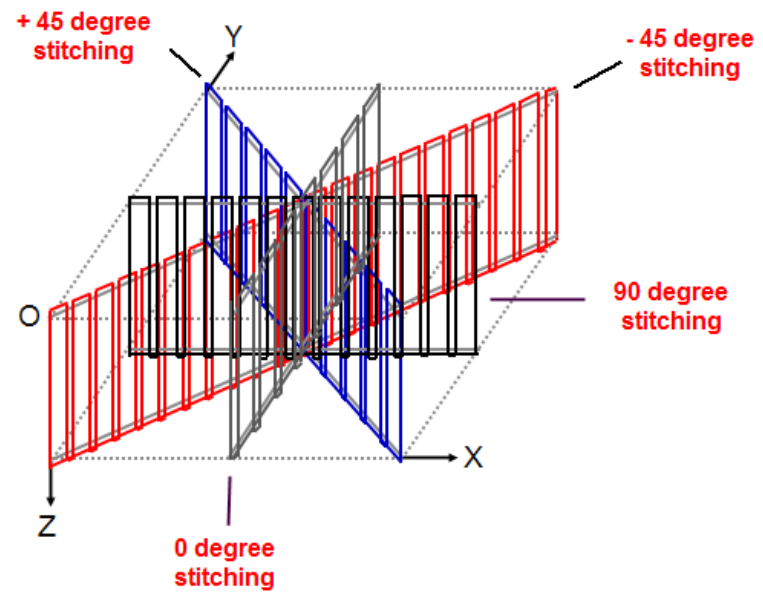

Figure 1. Schematic view of multi-stitching at $0^{\circ}, 90^{\circ}$ and $\pm 45^{\circ}$.

a1

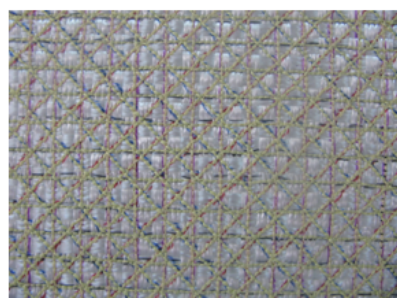

a2

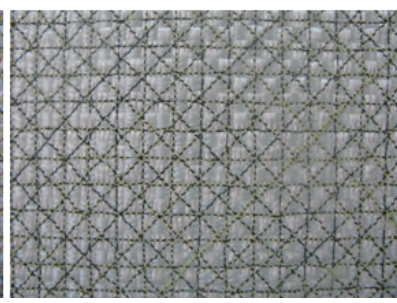

b1

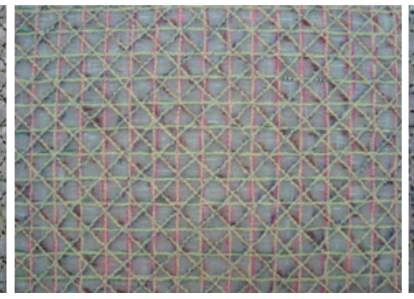

b2

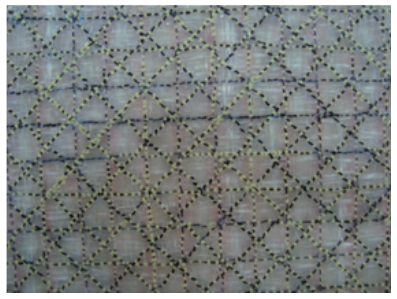

Figure 2. Views of multi-stitched 3D woven E-glass/polyester/nano silica preforms and composites. (a1) front face preform; (a2) back face preform; (b1) front face composite; (b2) back face composite. 


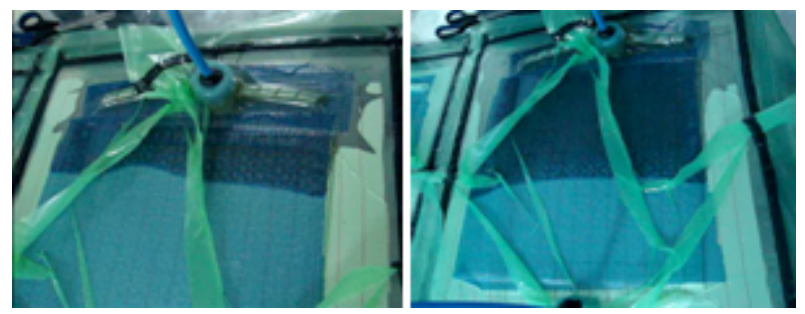

Figure 3. The infusion of resin to the E-glass woven preform during consolidation by VaRTM.

\section{$\underline{2.2 \text { Methods }}$}

\section{Tensile Test}

The tensile strength tests of the composite structures were performed on a Shimadzu AG-XD 50 (Japan) tester equipped with Trapezium ${ }^{\circledR}$ software based on ASTM D3039-76 [35]. The tensile testing speed was $2 \mathrm{~mm} / \mathrm{min}$. The test dimensions were $25.4 \mathrm{~mm}$ (width) $\times 227 \mathrm{~mm}$ (length) with a $50-\mathrm{mm}$ gauge length for both bottom and top of the specimen. The tab parts of the samples were made by using the same sample piece, and epoxy resin was used as adhesive. The tensile load applied to each sample was an warp $\left(0^{\circ}\right)$ and weft $\left(90^{\circ}\right)$ directions. In addition, the off-axis tensile load applied to each sample was at an angle $\pm 45^{\circ}$ to the warp $\left(0^{\circ}\right)$ and weft $\left(90^{\circ}\right)$ directions. Also, relative humidity and temperature of the testing laboratory were $60 \pm 5 \%$ and $22 \pm 1^{\circ} \mathrm{C}$. After the tensile load was applied to the composite structures, they were examined by an optical microscope (Olympus SZ61, Japan) and a digital camera (Canon-Powershot G9-12.1 Megapixel, x 6.0 Optical Zoom, Japan). The damaged areas in each of the sample's front surface were measured by an image analyzing software (Image Pro-Plus, MediaCybernetics, USA).

\section{Bending Test}

The three-point bending strength test of the composite structures was performed on a Shimadzu AG-XD 50 (Japan) tester equipped with Trapezium $^{\circledR}$ software based on ASTM D790-90 [36]. The bending testing speed was $1.3 \mathrm{~mm} / \mathrm{min}$. The test dimensions were $25.4 \mathrm{~mm}$ (width) $\times 80 \mathrm{~mm}$ (length) The L/d (support span length-to-thickness) ratio was 16/1. The bending load applied to each sample was the warp $\left(0^{\circ}\right)$ and weft $\left(90^{\circ}\right)$ directions, respectively. Formulations of bending strength, modulus, and strain were presented, respectively, as follows.

$$
\begin{aligned}
& S=3 P L / 2 b d^{2} \\
& E=L^{3} \mathrm{~m} / 4 b d^{3}
\end{aligned}
$$

$$
\varepsilon=\left(I_{1}-I_{0}\right) / I_{0}=\Delta / / I_{0}
$$

where $S$ is the bending strength in the outer fibers at midspan $\left(\mathrm{N} / \mathrm{m}^{2}\right)$ based on ASTM D790-90, $\mathrm{P}$ is the load at a given point on the load-deflection curve $(\mathrm{N}), \mathrm{L}$ is the support span $(m), b$ is the width of beam tested $(m), d$ is the depth of beam tested $(m), E$ is the modulus of elasticity in bending $\left(\mathrm{N} / \mathrm{m}^{2}\right), \mathrm{m}$ is the slope of the tangent to the initial straight-line portion of the load-deflection curve, $\varepsilon$ is the bending strain (\%), $\Delta l$ is the elongation $(\mathrm{mm}), \mathrm{I}_{1}$ is the material length after test $(\mathrm{mm})$, and $\mathrm{I}_{0}$ is the material initial length $(\mathrm{mm})$.

\section{Short Beam Test}

The short beam test of the composite structures was performed on a Shimadzu AG-XD 50 (Japan) tester equipped with Trapezium $^{\circledR}$ software based on ASTM D2344-00 [37]. The short beam testing speed was $1.0 \mathrm{~mm} / \mathrm{min}$. The test dimensions were considered as $25 \mathrm{~mm}$ (width) $\times 20 \mathrm{~mm}$ (length). The L/d (support span length-to-thickness) ratio was $4 / 1$. The short beam load applied to each sample was the warp $\left(0^{\circ}\right)$ and weft $\left(90^{\circ}\right)$ directions, respectively. The short beam strength was calculated based on the following relations.

$$
F^{s b s}=0.75 \times \frac{P_{m}}{b \times h}
$$

where $\mathrm{F}^{\mathrm{sbs}}$ is the short-beam strength (MPa), $\mathrm{P}_{\mathrm{m}}$ is the maximum load observed during the test $(\mathrm{N}), \mathrm{b}$ is the measured specimen width $(\mathrm{mm})$, and $\mathrm{h}$ is the measured specimen thickness $(\mathrm{mm})$.

\section{Low-Velocity Impact Test}

A drop-weight instrument (CEAST Fractovis Plus, Belgium), as shown in Figure 4(a), was used to subject the composite sample to impact at the center of each sample. For this study, the impact velocity was held at $2.672 \mathrm{~m} / \mathrm{s}$, and the total mass of the impactor was fixed at $5.45 \mathrm{~kg}$, resulting in a kinetic energy of $19.45 \mathrm{~J}$ for each impact. The collected data were stored after each strike by using a high-speed data collector (DAS 16000), and the impactor was returned to its original starting height, which was $0.364 \mathrm{~m}$, as seen in Figure 4(b). The sample holder was rigidly attached to the frame of the testing instrument so that the tup struck the target each time at the same location. The tup chosen for this study was circular cylindrical, with a 19-mm diameter and a hemispherical nose, as seen in Figure 4 (b). The work of tup deformation is neglected. A rectangular composite panel with dimensions of $100 \mathrm{~mm}$ (width) $\times 150 \mathrm{~mm}$

\begin{tabular}{|c|c|c|c|c|c|c|}
\hline \multirow[b]{2}{*}{ Nano material } & \multirow{2}{*}{$\begin{array}{c}\text { Amount of nano } \\
\text { material } \\
\text { (\% wt.) }\end{array}$} & \multirow{2}{*}{$\begin{array}{c}\text { Hardener } \\
\text { (MEKP) } \\
(\%) \\
\end{array}$} & \multirow{2}{*}{$\begin{array}{c}\text { Catalyzer } \\
\text { (CoNAP) } \\
(\%) \\
\end{array}$} & \multicolumn{2}{|c|}{ Mixing conditions } & \multirow{2}{*}{$\begin{array}{l}\text { Gelling } \\
\text { time } \\
\text { (min) }\end{array}$} \\
\hline & & & & $\begin{array}{c}\text { Mechanical } \\
\text { mixing } \\
(\mathrm{min}, \mathrm{rpm})\end{array}$ & $\begin{array}{c}\text { Ultrasonic } \\
\text { mixing } \\
\left(\min ,{ }^{\circ} \mathrm{C}\right)\end{array}$ & \\
\hline $\begin{array}{c}\text { Silica }\left(\mathrm{SiO}_{2}\right) \\
\text { (nano sphere) }\end{array}$ & 5 & 4 & 0.3 & $\begin{array}{c}2 \mathrm{~min} . \\
20.000 \mathrm{rpm}\end{array}$ & $\begin{array}{l}5 \min . \\
25^{\circ} \mathrm{C}\end{array}$ & 60 \\
\hline
\end{tabular}
(length) was clamped between two thick aluminum plates and fixed to a rigid base to prevent slippage of the sample, as seen

Table 2. Mixing conditions of nano silica in polyester resin for VaRTM. 
in Figure 4(c). The size of the aluminum plates was $112 \mathrm{~mm}$ (width) $\times 153 \mathrm{~mm}$ (length) $\times 30 \mathrm{~mm}$ (thickness), and the size of window frame was $75 \mathrm{~mm}$ (width) $\times 125 \mathrm{~mm}$ (length) $\times 20$ $\mathrm{mm}$ (thickness). In addition, the size of a circular opening in the clamping plate was $40 \mathrm{~mm}$. The low-velocity impact test on the composite sample panel was conducted based on ASTM D7136/D7136M-07 [38].

\section{Results and Discussion}

\section{Density and fiber volume fraction results}

The density and fiber volume fraction results of multistitched 3D woven E-glass/polyester/nanosilica (MNS) composite are presented in Table 3. As seen in Table 3, the total fiber weight fractions of the MNS composite structure is $68.80 \%$. Void contents (weight) of MNS composite structure is $2.7 \%$. Figure 5 shows the void of composites in the stitching area. The density, total fiber weight fraction, and the void content results indicated that partly stitching and partly composite process caused local misalignment and uneven fiber placement in the MNS structure.

\section{Tensile results}

The warp-weft and off-axis directional tensile test results of MNS composite are presented in Table 4. Figure 6 shows the stress-strain curves of MNS composite structures.

As seen in Table 4, the warp, weft, and off-axis $\left( \pm 45^{\circ}\right)$ directional tensile strengths of the MNS composite structures were $238,204,86$, and $80 \mathrm{MPa}$, respectively. The warp and weft directional tensile strengths of the MNS structures were more than 2.5 times higher than those of the off-axis directions because of the off-axis position of the fibers in the structure. In addition, the warp directional tensile strength of the MNS
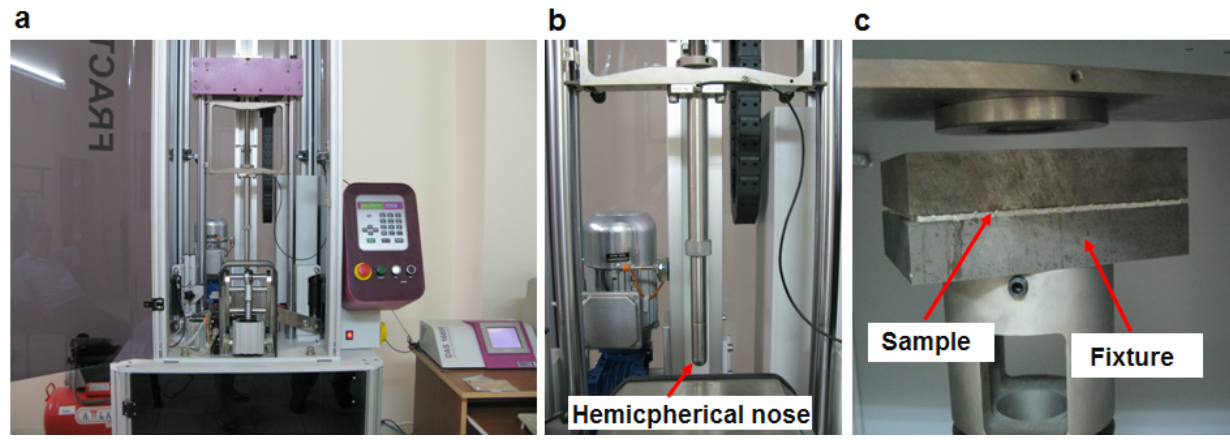

Figure 4. Drop-weight testing instrument. (a) front view; (b) tup assembly; (c) sample holder close.

Table 3. Density and fiber volume fraction results of multi-stitched 3D woven E-glass/polyester/nano silica composites.

\begin{tabular}{|c|c|c|}
\hline \multirow{2}{*}{ Stitching yarn/Stitching density } & & Multi-stitched/Nano Silica (MNS) \\
\hline Average thickness (mm) & & Kevlar129/6step/cm \\
\hline Measured density (g/cm3) & & $3.2 \pm 0.1$ \\
\hline \multirow{2}{*}{ Total fiber volume fraction (\%) } & Weight & 1.8 \\
\cline { 2 - 3 } & Volume & 68.8 \\
\hline \multirow{2}{*}{ Fiber volume fraction (\%) } & Weight & 48.3 \\
\cline { 2 - 3 } & Volume & 65.7 \\
\hline \multirow{2}{*}{ Stitching yarn volume fraction (\%) } & Weight & 47.2 \\
\cline { 2 - 3 } & Volume & 3.1 \\
\hline Void content (\%) & & 1.0 \\
\hline
\end{tabular}

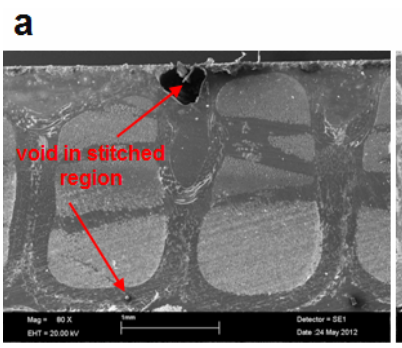

b

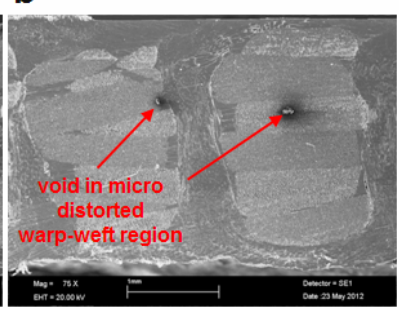

C

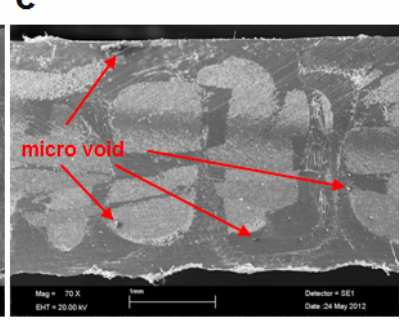

Figure 5. SEM photos of multistitched 3D woven E-glass/polyester/nanosilica composites (a) at $0^{\circ}$ (warp, the scale bar: $1 \mathrm{~mm}$, magnification: $\times 80$ ) [39]; (b) at $+45^{\circ}$ (the scale bar: $1 \mathrm{~mm}$, magnification: $\times 75$ ); (c) at $-45^{\circ}$ (the scale bar: $1 \mathrm{~mm}$, magnification: $\times 70$ ). 
Table 4. Tensile results of multi-stitched 3D woven E-glass/polyester/nano silica composites.

\begin{tabular}{|c|c|c|c|c|}
\hline \multirow{2}{*}{} & \multicolumn{4}{|c|}{ Multi-stitched/Nano Silica (MNS) } \\
\cline { 2 - 5 } & $\begin{array}{c}\text { Tensile strength } \\
\text { (MPa) }\end{array}$ & $\begin{array}{c}\text { Tensile modulus } \\
\text { (GPa) }\end{array}$ & $\begin{array}{c}\text { Tensile strain } \\
\text { (\%) }\end{array}$ & $\begin{array}{c}\text { Damaged area } \\
\left(\mathbf{m m}^{2}\right)\end{array}$ \\
\hline Warp & 238.8 & 7.3 & 4.7 & 382.8 \\
\hline Weft & 204.1 & 5.5 & 4.7 & 570.1 \\
\hline $\mathbf{+ 4 5}^{\circ}$ & 86.8 & 3.8 & 12.2 & 495.0 \\
\hline $\mathbf{4 5}^{\circ}$ & 80.1 & 3.7 & 10.9 & 465.9 \\
\hline
\end{tabular}

a

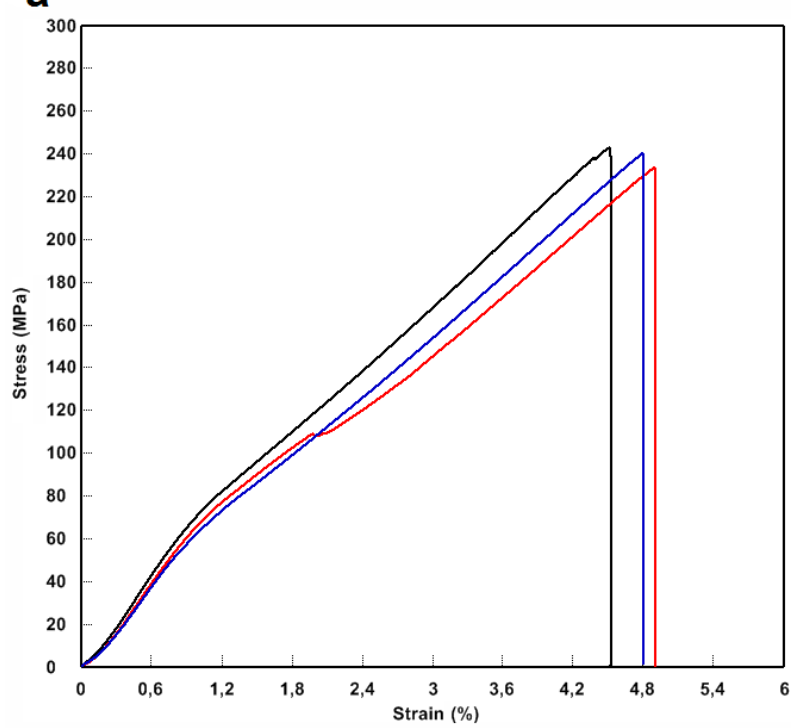

Figure 6. Tensile stress-strain curves of multi-stitched 3D woven E-glass/polyester/nano silica composites at warp direction.

structure was $14 \%$ higher than that of the weft direction because of the processing degradation during formation that caused inconsistent pick density. The $+45^{\circ}$ and $-45^{\circ}$ directional tensile strengths of the MNS structures were almost equal. The warp, weft, and off-axis $\left( \pm 45^{\circ}\right)$ directional tensile modulus of the MNS composite structures were 7.3, 5.5, 3.8, and 3.3 GPa, respectively. The warp and weft directional tensile modulus of the MNS structures were almost two times higher than those of the off-axis directions because of the off-axis position of the fibers in the structure. In addition, the warp directional tensile modulus of the MNS structure was about $25 \%$ higher than that of the weft direction because of the processing degradation during formation that caused inconsistent pick density. The $+45^{\circ}$ and $-45^{\circ}$ directional tensile strengths of the MNS structures were almost equal. The warp, weft, and off-axis $\left( \pm 45^{\circ}\right)$ directional tensile strain of the MNS composite structures were $4.7 \%, 4.7 \%, 12.2 \%$, and $10.9 \%$, respectively. The off-axis directional tensile strains of the MNS structure were almost 2.5 times higher than those of the warp and weft directions because of the fiber position in the structure that caused large in-plane fiber distortions and the out-of-plane fiber placement by multistitching. The warp and weft directional tensile strains of the MNS structure were equal. In addition, the differences of tensile strains between the $+45^{\circ}$ and $-45^{\circ}$ directions were insignificant.

\section{Bending results}

The warp and weft directional bending test results of the MNS composite structure are presented in Table 5. Figure 7(a) and (b) shows the stress-strain curves of MNS composite structures. The bending stress-strain curve of the MNS structure became slightly an incline curve, and the breaking point of the curve slightly decreased as shown in Figure 7 (a) and (b).

As seen in Table 5, the warp and weft directional bending strengths of the MNS composite structures were 239 and 194 $\mathrm{MPa}$, respectively. The warp directional bending strengths of the MNS structure was about $20 \%$ higher than that of the weft direction. The warp and weft directional bending modulus of the MNS composite structures were 9.7 and $8.4 \mathrm{GPa}$, respectively. The warp directional bending modulus of the MNS structure was about $14 \%$ higher than that of the weft direction. The differences between warp and weft were due to the processing degradation during the formation and consolidation. The warp and weft directional bending strain of the MNS composite structures were $2.9 \%$ and $3.7 \%$, respectively. The warp directional bending strain of the MNS structure was about $28 \%$ less compared to the weft direction because of the fabric stitching and consolidation. 
Table 5. Bending test results of multistitched 3D woven E-glass/polyester/nanosilica composites.

\begin{tabular}{|c|c|c|c|c|}
\hline & \multicolumn{4}{|c|}{ Multi-stitched/Nano Silica (MNS) } \\
\cline { 2 - 5 } & $\begin{array}{c}\text { Bending strength } \\
(\mathbf{M P a})\end{array}$ & $\begin{array}{c}\text { Bending modulus } \\
(\mathbf{G P a})\end{array}$ & $\begin{array}{c}\text { Bending strain } \\
(\%)\end{array}$ & $\begin{array}{c}\text { Damaged area } \\
(\mathbf{m m})\end{array}$ \\
\hline Warp & 239.1 & 9.7 & 2.9 & 104.7 \\
\hline Weft & 194.6 & 8.4 & 3.7 & 183.3 \\
\hline
\end{tabular}

a

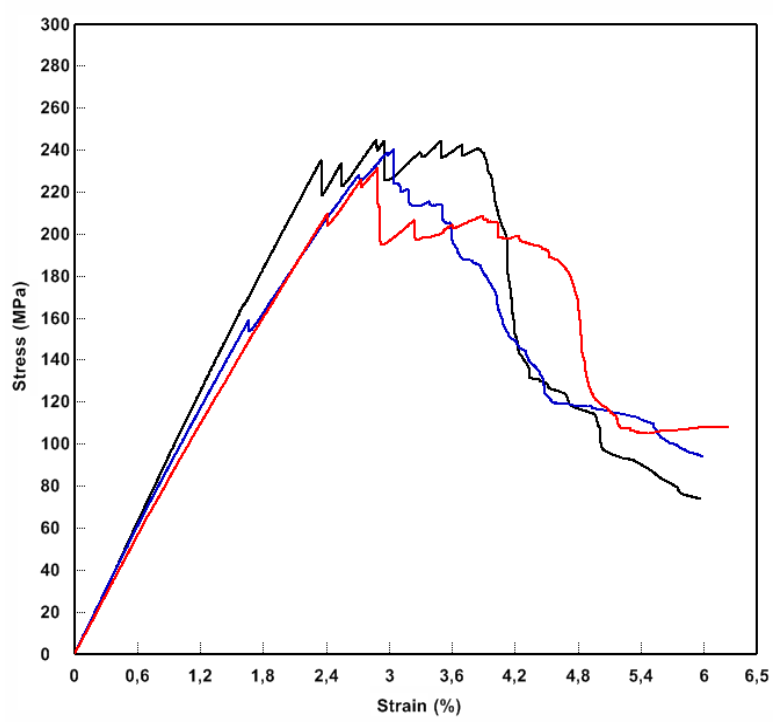

b

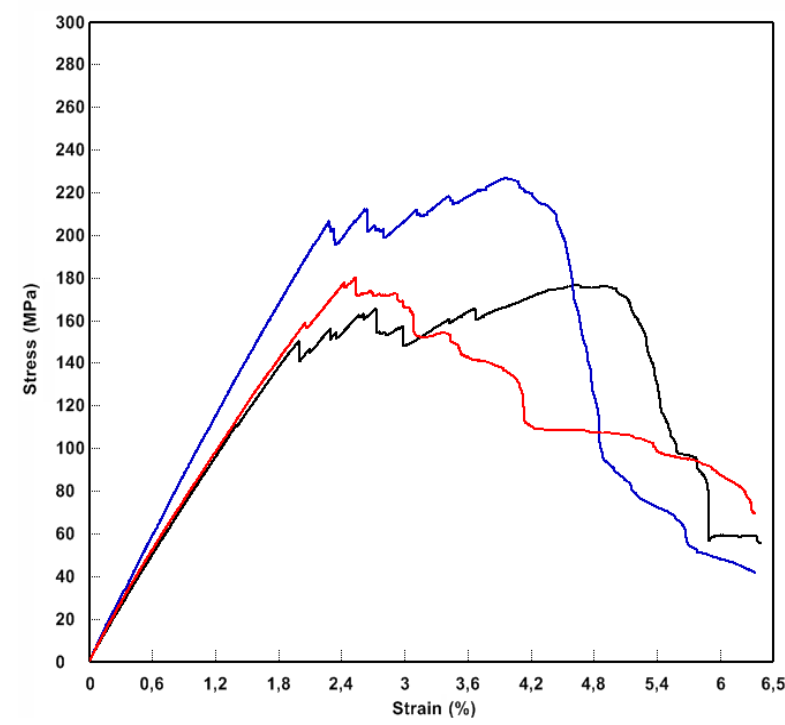

Figure 7. Bending test stress-strain curves of the multi-stitched 3D woven E-glass/polyester/nanosilica composites: (a) warp and (b) weft.

\section{Short beam results}

The warp and weft directional short-beam test results of the MNS composite structure are presented in Table 6. Figure 8 shows the load-displacement curves of MNS composite structures.

As seen in Table 6, the warp and weft directional short-beam strengths of the MNS composite structures were 23.2 and 19.5 $\mathrm{MPa}$, respectively. The warp directional short-beam strength

\section{a}

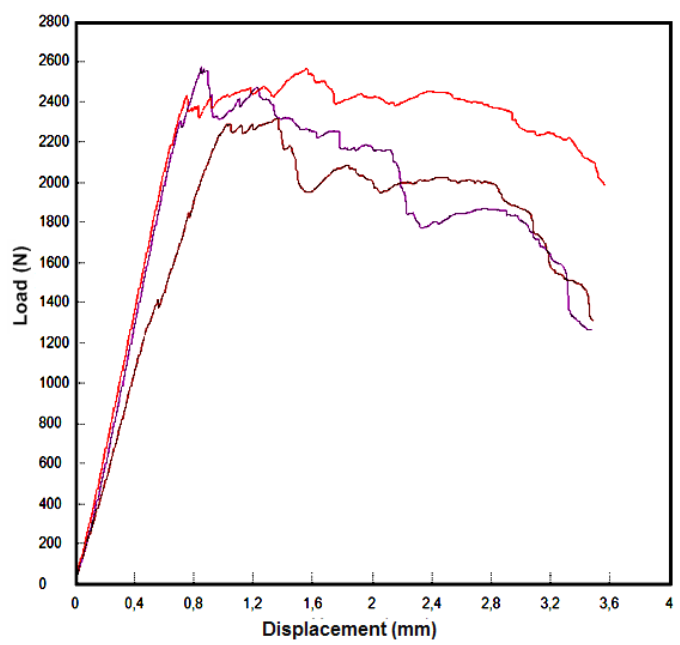

Table 6. Short beam strength test results of multi-stitched 3D woven E-glass/polyester/nano silica composites.

\begin{tabular}{|c|c|c|}
\hline \multirow{2}{*}{} & \multicolumn{2}{|c|}{ Multi-stitched/Nano Silica (MNS) } \\
\cline { 2 - 3 } & $\begin{array}{c}\text { Maximum load } \\
\text { (N) }\end{array}$ & $\begin{array}{c}\text { Short beam strength } \\
\text { (MPa) }\end{array}$ \\
\hline Warp & 2482.2 & 23.2 \\
\hline Weft & 2089.3 & 19.5 \\
\hline
\end{tabular}

b

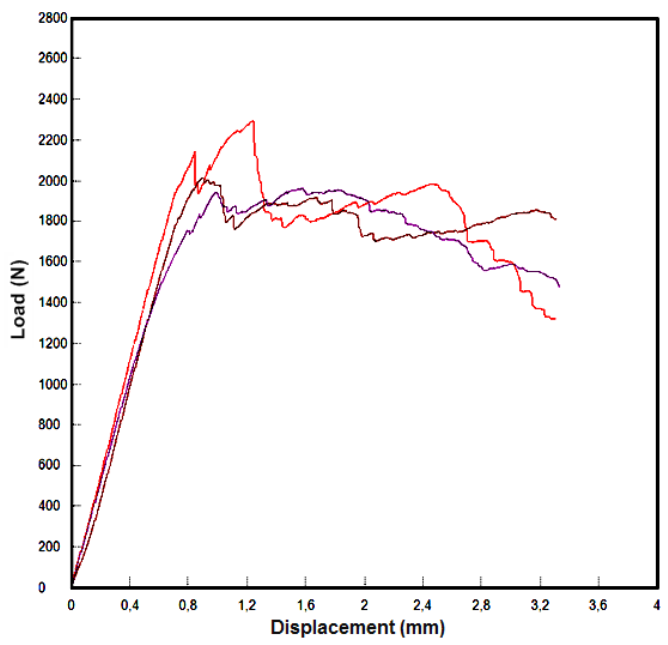

Figure 8. Short beam load-displacement curves of multi-stitched 3D woven E-glass/polyester/nano silica composites. (a) warp; (b) weft. 
of the MNS structure was about $16 \%$ higher than that of the weft direction. The reason for this slight difference between warp and weft was more likely due to the fabric stitching and consolidation.

\section{Low-velocity impact results}

The low-velocity impact load results of the MNS composites are presented in Table 7. Figure 9 shows the low-velocity impact peak load-time curves of the MNS composite structures for $19.45 \mathrm{~J}$ impact energy. The peak load-contact time of the MNS composite structure was $6.02 \mathrm{kN}$ and $10.5 \mathrm{~ms}$, respectively.

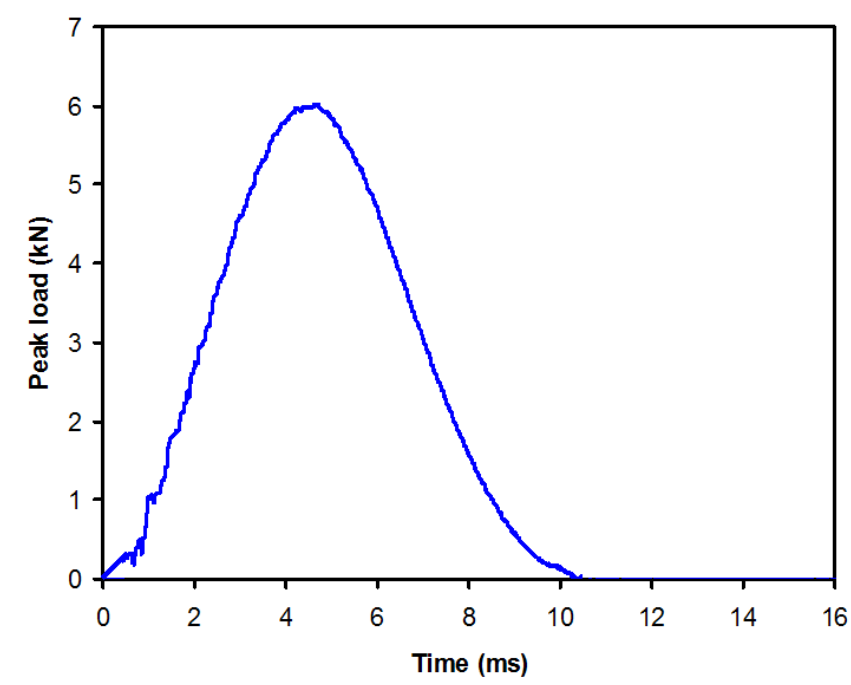

Figure 9. Low velocity impact peak load-time curves of the multistitched 3D woven E-glass/polyester/nanosilica composites for $19.45 \mathrm{~J}$ of impact energy.

\section{Failure results after tensile test}

Failure results of the developed MNS composite structure after tensile test are presented in Table 4. Figure 10 shows the front face and the cross-sectional views of MNS composites after tensile load was applied on warp-weft and off-axis directions. It was observed that the damaged area of the MNS composite in warp direction was lower than that of the weft and off-axis directions.

The failure of warp and weft directional MNS composite structures was observed as a form of matrix breakages, and partial fiber breakages and complete yarn (tow) breakages in their surfaces. In addition, the MNS structure had a very limited delamination in its cross section. The failure was confined at a narrow area because of the multistitching. This resulted in the catastrophic fiber breakages in the normal direction of the applied load of the structure. In addition, interlayer failure was observed at a local region of cross section of the composite structure and did not propagate around the region. On the other hand, it was observed that the failure of MNS structure showed more brittle behavior. It could be considered that MNS structures showed the damage-tolerance behavior under the static tensile load.

The failure of $\pm 45^{\circ}$ directional MNS composite structure was observed as a form of matrix breakages and partial fiber breakages in their surfaces. In addition, the MNS structure had shrinkage in width and delamination in their cross sections. The failure under the off-axis tensile load was confined at a narrow area because of multiple stitching. This resulted in the catastrophic fiber breakages in the normal direction of the applied load of the structure. In addition, interlayer failure was observed at the local region of cross section of the structure and did not propagate around the region. On the other hand, it was observed that the failure of $\pm 45^{\circ}$ directional MNS structure showed more brittle behavior.

\section{Failure results after bending test}

Failure results of the developed MNS composite structure after bending test are presented in Table 5 . Figure 11 shows the front face and the cross-sectional views of MNS composites after bending load was applied on warp and weft directions. It was observed that the damaged area of the MNS composite in warp direction was lower than that of the weft directions.

As seen in Figure 11, the failure of warp and weft directional MNS composite structures was observed as a form of matrix breakages, and partial and complete filaments and yarn (tow) breakages in their surfaces. In addition, the MNS structure had a local delamination in their cross sections, and the delamination did not propagate to the large areas because of multiple stitching. The warp and weft directional bending load was confined at a narrow area in which the catastrophic failure lead to the damage as a form of matrix breakages, fiber-matrix pull-out, and local multiple fiber breakages. On the other hand, it was observed that the failure of the MNS structure showed more brittle behavior. It could be considered that the MNS

Table 7. Drop test results of multi-stitched 3D woven E-glass/polyester/nano silica composites.

\begin{tabular}{|c|c|c|}
\hline & & Multi-stitched/Nano Silica (MNS) \\
\hline Peak load (kN) & & 6.02 \\
\hline Contact time (ms) & & 10.5 \\
\hline \multirow{2}{*}{ Damaged area $\left(\mathrm{mm}^{2}\right)$} & Front face & 182.5 \\
\hline & Back face & 230.9 \\
\hline Impact energy (J) & & 19.5 \\
\hline $\begin{array}{c}\text { Dimensions }(\mathrm{mm}) \\
\text { (width } \times \text { length } \times \text { thickness) }\end{array}$ & & $100 \times 150 \times 3.2$ \\
\hline
\end{tabular}


a
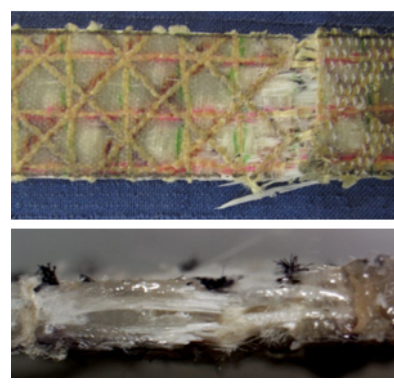

b

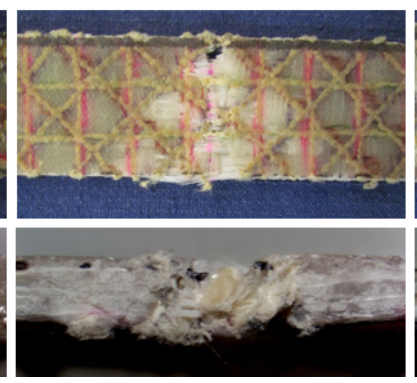

C

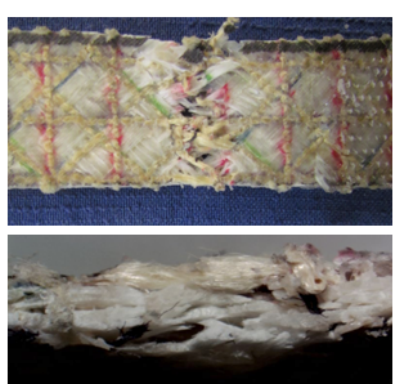

d

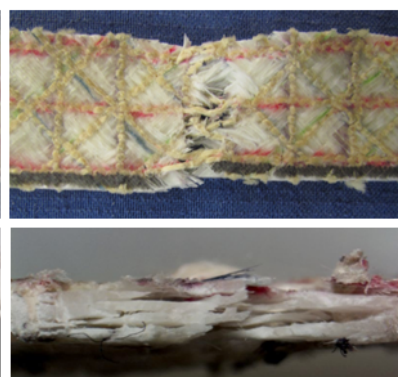

Figure 10. Front face (digital photos, top) and cross sectional (microscopic photos at $\times 6.7$ magnification, bottom) views of multi-stitched $3 \mathrm{D}$ woven E-glass/polyester/nano silica composites after tensile test. (a) warp; (b) weft; (c) $+45^{\circ}$; (d) $-45^{\circ}$.

a
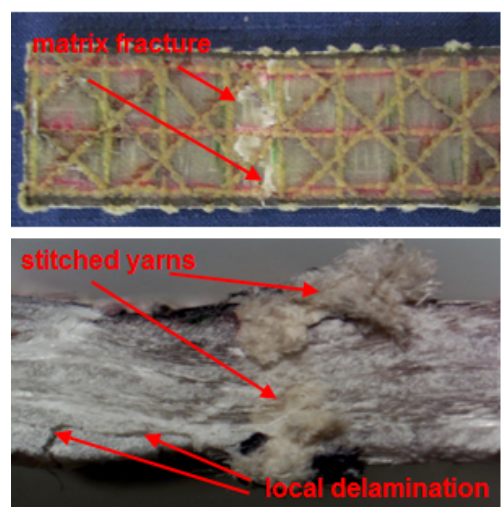

b
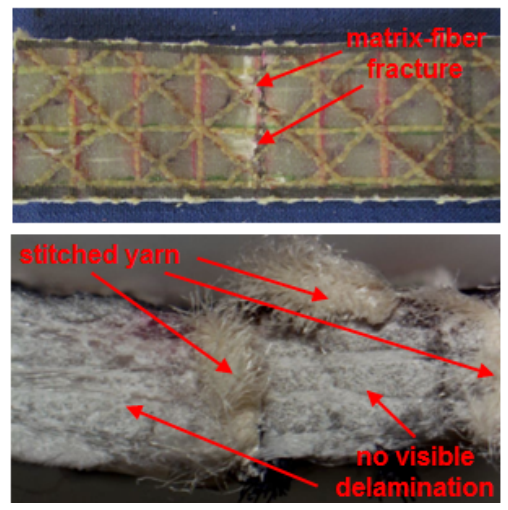

Figure 11. Front face (digital photos, top) and cross sectional (microscopic photos at $\times 6.7$ magnification, bottom) views of multi-stitched $3 \mathrm{D}$ woven E-glass/polyester/nano silica composites after bending test. (a) warp; (b) weft.

structure showed a damage tolerance behavior under the static bending load.

\section{Failure results after short beam test}

Failure results of the developed MNS composite structure after short-beam test are presented in Table 6. Figure 12 shows the front face and the cross-sectional views of MNS composites after short-beam load was applied on warp and weft directions.

As seen in Figure 12, the failure of warp and weft directional MNS structures was observed as a form of major matrix breakages, and partial and complete filaments and yarn (tow) breakages on their surfaces. In addition, the MNS composite structure had interlaminar shear failure between layers in their cross sections but the failure did not propagate to the large areas. The interlaminar shear failure occurred around the stitching yarn regions at a small area. Also, there is a flexure failure on the top surface of the structure as a form of compression and at the bottom surface as a form of tension where the intrayarn openings were observed.

\section{Failure results after low-velocity impact test}

Failure results of developed MNS composite structure after low-velocity impact test are presented in Table 7. Figure 13 shows the front and back face failures of MNS composites after impact load was applied. It was observed that the back face damaged area of the MNS composite was higher than that of the back face.
The damaged areas in the structure generally showed two regions as damages in the center and in the surrounding area. The measured damaged areas included both center and surrounding area. Low-velocity impact caused an indentation in the center of the damaged area in front face of the MNS structures. However, in the center of the back face of the MNS structures, warp and weft directional minor fiber splitting was obtained. In the surrounding area of the front and back face damaged zones, fiber-matrix debonding expanded radially, and minor matrix breakages were observed. In addition, it was observed that stitching confined the damage zone in the surrounding area, in particular, suppressed fiber breaking propagation to the damaged area. Future research will be conducted on the damage sizes of each layer and fiber breakage patterns in each subsequent layer.

These results were considered that the multistitching suppressed the impact energy to a relatively small area of the composite structure. Therefore, the MNS composite structures showed better damage-resistance performance.

\section{Conclusions}

MNS composites were developed and tested against the mechanical static and low-velocity impact load.

It was found that the warp and weft directional tensile strength and modulus of MNS structure were higher than those of the off-axis directions because of the off-axis fiber orientation in 
a
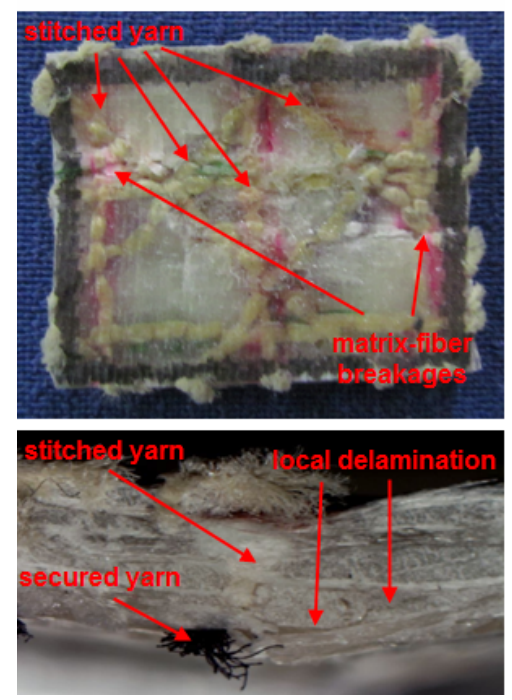

b
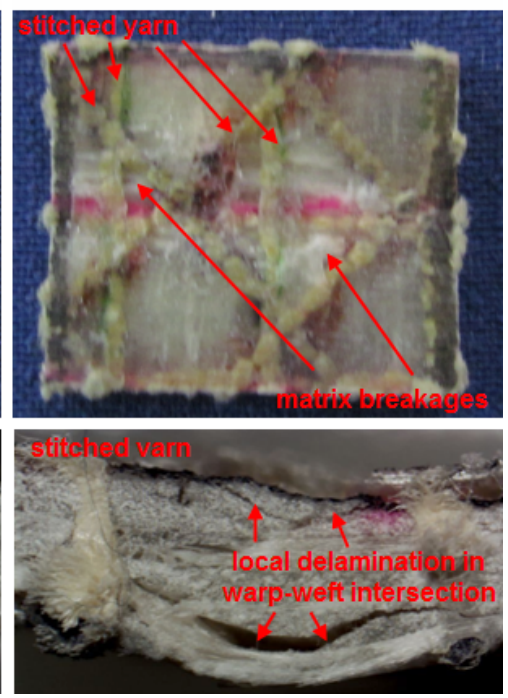

Figure 12. Front face (digital photos, top) and cross sectional (microscopic photos at $\times 6.7$ magnification, bottom) views of multi-stitched $3 \mathrm{D}$ woven E-glass/polyester/nano silica composites after short beam strength test. (a) warp; (b) weft.

a

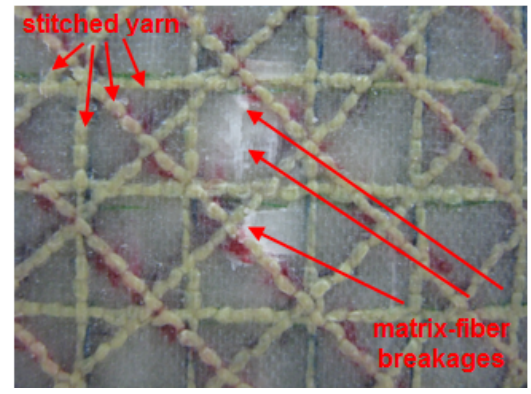

b

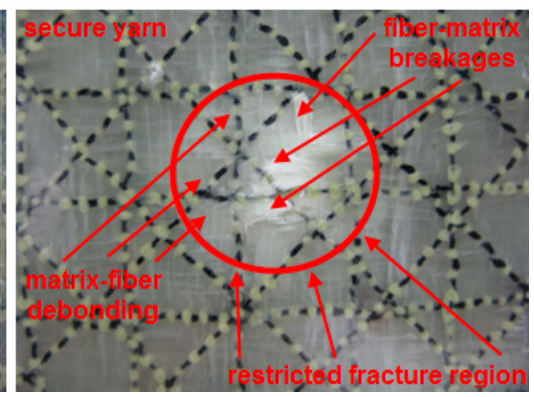

Figure 13. Failure on multi-stitched 3D woven E-glass/polyester/nano silica composites after low velocity impact load. (a) front face; (b) back face.

the structure plane. On the other hand, the warp and weft directional tensile strains of MNS structure were lower than those of off-axis direction. It was also generally found that the warp directional tensile strength and modulus of the MNS composite structures were slightly higher than that of the weft direction. In addition, it was found that there was not big a difference between warp and weft directional bending and short-beam strengths of MNS structure. Under low-velocity impact load, the MNS structure had a small damaged area in the front face, but it had especially a very small damaged area in the back face. This indicated that adding the silica base nanomaterial to the composite structures caused a stiff front face that resisted the impact load on this face. Contrarily, the multistitching confined the damaged zone in the surrounding area, in particular, suppressed the fiber breaking propagation to the damaged area.

The failure of warp and weft directional MNS composite structures was matrix breakages, and partial and complete filaments and yarn (tow) breakages in their surfaces. They had a local delamination in their cross sections, and the delamination did not propagate to the large areas because of multiple stitching. The failure was confined at a narrow area because of multistitching and resulted in the catastrophic fiber breakages in the normal direction of the applied load of the stitched structures. The off-axis MNS structure showed shrinkage in width and delamination in their cross sections. In addition, MNS structure under short-beam load had interlaminar shear failure between layers in their cross sections, but it did not propagate to the large areas.

The results from the study indicated that the multistitching and the addition of nanosilica in the multistitched structure suppressed the impact energy relatively at a small area of the composite structure and improved its damage resistance. However, more detailed study is required on the interface properties between nanomatrix, nanofiber, and nanofiber/matrix on the MNS composite structures, which will be conducted in the future.

\section{Acknowledgments}

This work was partly supported by the Erciyes University Scientific Research Unit (EUBAP) under contract number EUBAPFBD-10-3383. The authors would like to thank the Scientific Research Department of Erciyes University for their invaluable support. The authors would like to thank Prof. Dr. Mustafa Guden for allowing the use of composite laboratory facilities in IYTE for this project. 


\section{References}

[1] Dow, M. B., Dexter, H. B. (1997). Development of Stitched, Braided and Woven Composite Structures in the ACT Program at Langley Research Centre (1985 to 1997). National Aeronautics and Space Administration Technical Publication No. 97-206234, Langley Research Center, Hampton, Virginia.

[2] Kamiya, R., Cheeseman, B. A., Popper, P., Chou, T. W. (2000). Some recent advances in the fabrication and design of three dimensional textile preforms: A review. Composite Science and Technology, 60(1), 33-47.

[3] Bilisik, K., Yilmaz, B. (2012). Multiaxis multilayered noninterlaced/non-z E-glass/polyester preform and analysis of tensile properties of composite structures by statistical model, Textile Research Journal, 82(4), 336-351.

[4] Kang, T. J., Lee, S. H. (1994). Effect of stitching on the mechanical and impact properties of woven laminate composite, Journal of Composite Materials, 28(16), 15741587.

[5] Wu, E., Wang, J. (1995). Behavior of stitched laminates under in-plane tensile and transverse impact loading, Journal of Composite Materials, 29(17), 2254-2279.

[6] Dickinson, L. C., Farley, G. L., Hinders, M. K. (1999). Prediction of effective three-dimensional elastic constants of translaminar reinforced composites, Journal of Composite Materials, 33(11), 1002-1029.

[7] Tan, K. T., Watanabe, N., Iwahori, Y. (2012). Impact damage resistance, response and mechanisms of laminated composites reinforced by through-thickness stitching, International Journal of Damage Mechanics, vol. 21(1), 51-80.

[8] Bilisik, K. (2010). Multiaxis $3 D$ woven preform and properties of multiaxis $3 D$ woven and $3 D$ orthogonal woven carbon/epoxy composites, Journal of Reinforced Plastics and Composites, 29(8), 1173-1186.

[9] Mohamed, M. H., Bilisik, A. (1995). Multilayered 3D fabric and method for producing, US Patent 5465760.

[10] Wichmann, M.H.G., Sumfleth, J., Gojny, F.H., Quaresimin, M., Fiedler, B., Schulte, K. (2006). Glass-fibre-reinforced composites with enhanced mechanical and electrical properties - Benefits and limitations of a nanoparticle modified matrix, Engineering Fracture Mechanics, 73(16), 2346-2351.

[11] Greef, N.D., Gorbatikh, L., Lomov, S.V., Verpoest, I. (2011). Damage development in woven carbon fiber/epoxy composites modified with carbon nanotubes under tension in the bias direction, Composites Part A: Applied Science and Manufacturing, 42(11), 1635-1645.

[12] Thostenson, E.T., Li, C., Chou, T.W. (2005). Nanocomposites in context, Composites Science and Technology, vol. 65(3-4), 491-516.

[13] Wang, H.W., Zhou, H.W., Peng, R.D., Mishnaevsky, L. (2011). Nanoreinforced polymer composites: 3D FEM modeling with effective interface concept, Composites Science and Technology, 71(7), 980-990.

[14] Yong, V., Hahn, H.T. (2004). Processing and properties of SiC/vinyl ester nanocomposites, Nanotechnolgy, 15(9), 1338-1343.

[15]Patnaik, A., Satapathy, A., Mahapatra, S.S., Dash, R.R. (2009). A Comparative Study on Different Ceramic Fillers Affecting Mechanical Properties of GlassPolyester Composites, Journal of Reinforced Plastics and Composites, 28(11), 1305-1318.
[16] Davis, D. C., Wilkerson, J. W., Zhu, J., Hadjiev, V.G. (2011). A strategy for improving mechanical properties of a fiber reinforced epoxy composite using functionalized carbon nanotubes, Composites Science and Technology, 71(8), 1089-1095.

[17] Zhu, J., Imam, A., Crane, R., Lozano, K., Khabashesku, V.N., Barrera, E.V. (2007). Processing a glass fiber reinforced vinyl ester composite with nanotube enhancement of interlaminar shear strength, Composites Science and Technology, vol. 67(7-8), 1509-1515.

[18] Seyhan, A.T., Gojny, F.H., Tanoglu, M., Schulte, K. (2007). Critical aspects related to processing of carbon nanotube/ unsaturated thermoset polyester nanocomposites, European Polymer Journal, 43(2), 374-383.

[19] Gojny, F.H., Wichmann, M.H.G., Fiedler, B., Schulte, K. (2005). Influence of different carbon nanotubes on the mechanical properties of epoxy matrix composites- $A$ comparative study, Composites Science and Technology, vol. 65(15-16), 2300-2308.

[20] Velmurugan, R., Solaimurugan, S. (2007). Improvements in Mode I Interlaminar Fracture Toughness and In-Plane Mechanical Properties of Stitched Glass/Polyester Composites, Composites Science and Technology, vol. 67(1), 61-69.

[21] Mouritz, A.P., Gallagher, J., Goodwin, A.A. (1997). Flexural and Interlaminar Shear Strength of Stitched GRP Laminates Following Repeated Impacts, Composites Science and Technology, 57(5), 509-522.

[22] Mouritz, A.P. (1996). Flexural Properties of Stitched GRP Laminates, Composites, 27A, 525-530.

[23] Zhao, N., Rodel, H., Herzberg, C., Gao, S.L. and Krzywinsky, S. (2009). Stitched Glass/PP Composite Part I: Tensile and Impact Properties, Composites Part A: Applied Science and Manufacturing, 40(5), 635-643.

[24] Mouritz, A.P. (2001). Ballistic Impact and Explosive Blast Resistance of Stitched Composites, Composites Part B: Engineering, 32(4), 431-439.

[25] Dransfield, K.A., Jain, L.K., Mai, Y.W. (1998). On the Effects of Stitching in CFRPS-I: Mode I Delamination Toughness, Composites Science and Technology, 58(6), 815-827.

[26] Trabelsi, W., Michel, L., Othomene, R. (2010). Effects of Stitching on Delamination of Satin Weave Carbon-Epoxy Laminates under Mode I, Mode II And Mixed-Mode I/II Loadings, Applied Composite Materials, 17(6), 575-595.

[27] Sankar, B.V., Sharma, S.K. (1997). Mode II Delamination Toughness of Stitched Graphite/Epoxy Textile Composites, Composites Science and Technology, 57(7), 729-737.

[28] Sharma, S.K., Sankar, B.V. (1997). Effect of Stitching on Impact and Interlaminar Properties of Graphite/Epoxy Laminates, Journal of Thermoplastic Composite Materials, 10(3), 241-253.

[29] Baucom, J.N., Zikry, M.A. (2005). Low-velocity impact damage progression in woven E-glass composite systems, Composites Part A: Applied Science and Manufacturing, 36(5), 658-664.

[30] Antonio, F.A, Marcelo, I.S., Neto, A.S. (2007). A study on nanostructured laminated plates behavior under lowvelocity impact loadings, International Journal of Impact Engineering, 34(1), 28-41.

[31] Bilisik, K., Yolacan, G. (2014). Experimental characterization of multistitched two dimensional (2D) woven E-glass/ polyester composites under low velocity impact load, Journal of Composite Materials, 48(17), 2145-2162. 
[32] ASTM D792-13. (2013). Standard Test Methods for Density and Specific Gravity (Relative Density) of Plastics by Displacement, ASTM International, West Conshohocken, PA, USA.

[33] ASTM D3171-11. (2014). Standard Test Methods for Constituent Content of Composite Materials, ASTM International, West Conshohocken, PA, USA.

[34] ASTM D2734-09. (2014). Standard Test Methods for Void Content of Reinforced Plastics, ASTM International, West Conshohocken, PA, USA.

[35] ASTM D3039-76. (2000). Standard Test Method for Tensile Properties of Polymer Matrix Composite Materials, ASTM International, West Conshohocken, PA, USA.

[36] ASTM D790-03. (2003). Standard Test Methods for Flexural Properties of Unreinforced and Reinforced Plastics and Electrical Insulating Materials, ASTM International, West Conshohocken, PA, USA.
[37] ASTM D2344-00. (2000). Standard Test Method for Short-Beam Strength of Polymer Matrix Composite Materials and Their Laminates, ASTM International, West Conshohocken, PA, USA.

[38] ASTM D7136/D7136M-15. (2007). Standard test method for measuring the damage resistance of a fiber-reinforced polymer matrix composite to a drop-weight impact event, ASTM International, West Conshohocken, PA, USA.

[39] Bilisik, K., Yolacan, G. (2015). Warp and Weft Directional Bending Properties of Multistitched Biaxial Woven E-Glass/ Polyester Nano Composites, Journal of Industrial Textiles, 45(1), 66-100. 